\title{
Development of the mesh clamp and its evaluation
}

\author{
W Roach Sandvik Mining and Rock Technology, Australia \\ M Rataj Sandvik Mining and Rock Technology, Australia \\ B Darlington Sandvik Mining and Rock Technology, Australia
}

\begin{abstract}
With mine owners and operators continuously looking to increase development rates and reduce extraction costs, whilst maintaining safety, the need to develop new innovative products has never been in higher demand.

Working with the mining industry, Sandvik has recently developed and released a mesh clamp, which is designed to work with Sandvik's MD and MDX bolt range. The mesh clamp enables the installation of mesh sheets to be quicker, safer and more cost-effective.

The major challenge of designing the mesh clamp was to keep the design simple whilst still meeting the requirements of installation flexibility and remaining inobtrusive to the surrounding work area.

After several design iterations were laboratory and field tested, a final concept was agreed upon. The systems performance of the mesh clamp and the mesh needed to be evaluated. This required the development of a unique laboratory test rig to simulate the relevant test environment and loading conditions.

Laboratory test results proved that the mesh clamp is stronger than the $100 \times 100 \times 5.6 \mathrm{~mm}$ welded wire mesh. The mesh and mesh clamp arrangements were tested until failure occurred, at full mesh load capacity, where the mesh and mesh clamp performed well as a system to absorb a minimum of $50 \mathrm{kN}$ with up to $250 \mathrm{~mm}$ of vertical mesh displacement.
\end{abstract}

Keywords: rockbolt, rock plate, mesh, ground support, surface support

\section{Introduction}

The demand for continuous improvements in development rates is always increasing and mesh plays a major role in the ground support process for both safety and efficiency. Confining the mesh to the rock wall in a way that allows the mesh to deform yet still reach its full load potential is challenging, particularly whilst remaining stiff enough to prevent the rock from bulking out until the mesh gives way due to failure or separation of the overlapped join (Figure 1).

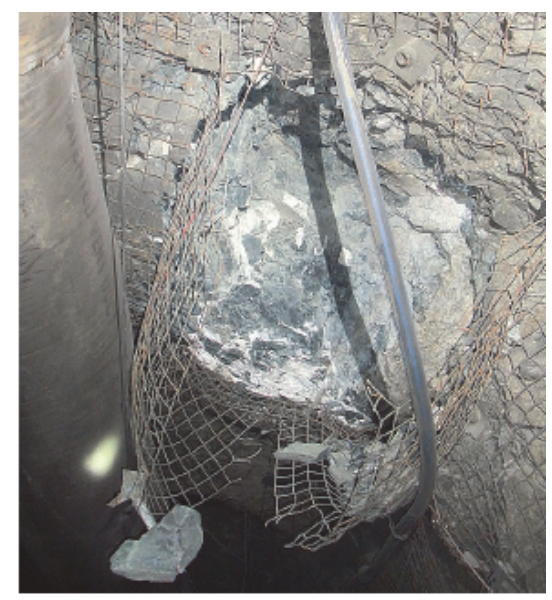

Figure 1 Mesh overlap join failure (Whiting 2017) 
There have been several previous attempts of retaining the overlapping new sheet of mesh without the need for installing a new rockbolt with varying levels of success. The main setbacks have been either arduous installation requirements, obtrusive parts after installation, flexibility of application, inadequate performance or combinations of each.

Sandvik first developed a meshing plate (Figure 2) in 2014 when they were purchased by a mine in Queensland, Australia. The meshing plate is composed of a $200 \mathrm{~mm}$ diameter domed plate, an internally threaded socket and an external hex drive. The meshing plate is a single-pass installation process, utilising conventional machinery and tools, onto a previously installed MD/MDX bolt. The meshing plate was not widely accepted due to a lack of flexibility to cope with uneven rock surfaces and its, sometimes fiddly, installation.

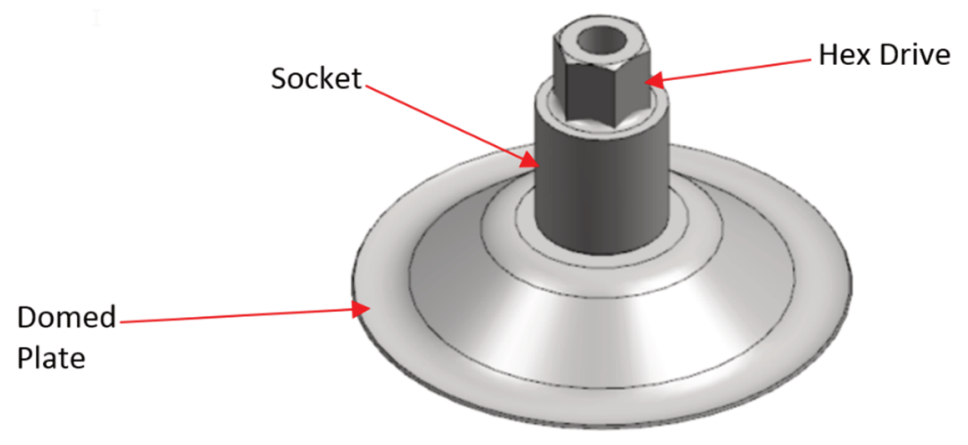

\section{Figure 2 The Sandvik meshing plate}

To improve on the performance, flexibility and ease of installation the mesh clamp was developed in 2018 (Figure 3). Like the meshing plate, the mesh clamp is a single pass installation utilising conventional machinery and tools; however, the mesh clamp has several key design improvements. The mesh supporting structure, the cage, is open allowing clearer vision to the nut on the existing bolt for the adapter sleeve to be aligned and screwed on. With the ability for the cage to mould to uneven surfaces and through the aid of a shear pin, the mesh clamp is able to supply additional clamping force to the mesh after installation. This provides consistent performance in a greater range of ground conditions.

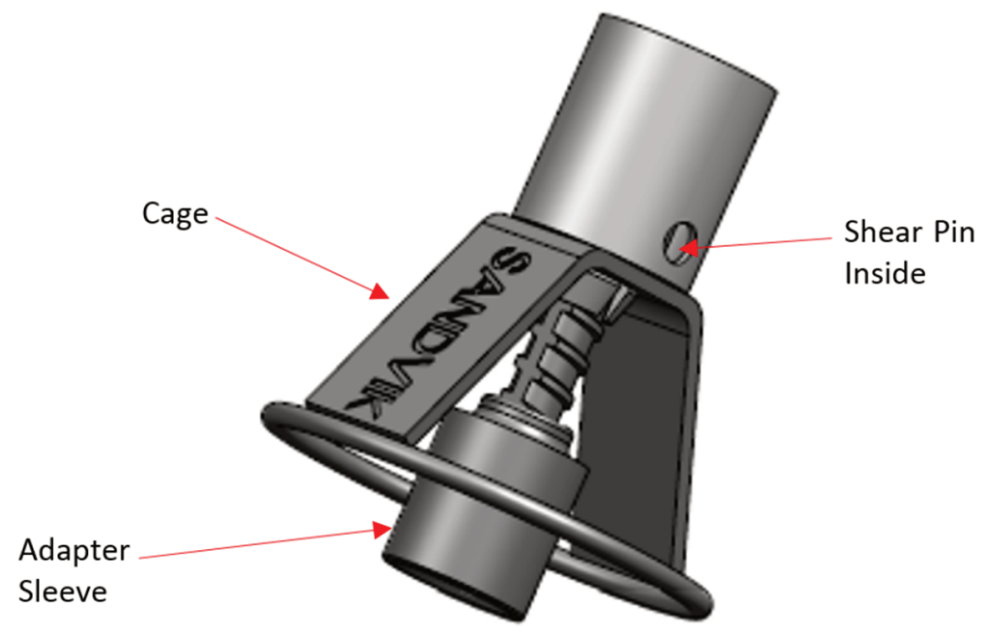

Figure 3 The Sandvik mesh clamp 


\section{Design methodology}

\subsection{Mesh clamp design criteria}

After a review of existing products and in consultation with customers, the mesh clamp design criteria were established:

- The mesh must be the first component to fail.

- The strength of the mesh sheet must not be compromised by the mesh clamp.

- The installation must be user friendly.

- The mesh sheet could be picked up and manoeuvred into position by the mesh clamp.

- Ensure the overlapping mesh is installed firmly against the existing mesh.

- The performance was to be flexible over varying surface conditions.

Initial concepts were prototyped and evaluated in the laboratory for clamping and picking up mesh. Once a concept had passed these preliminary functionality tests, further prototypes were manufactured for field trials. After customer feedback from field trials, and several iterations, a concept was trialled in a development cycle.

The mesh clamp is installed following six simple steps:

Step 1: Position the new sheet of mesh over the last existing row of MD/MDX bolts.

Step 2: Install the mesh clamp in the driver/dolly.

Step 3: Align the mesh clamp onto the existing centre MD/MDX bolt (Figure 4).

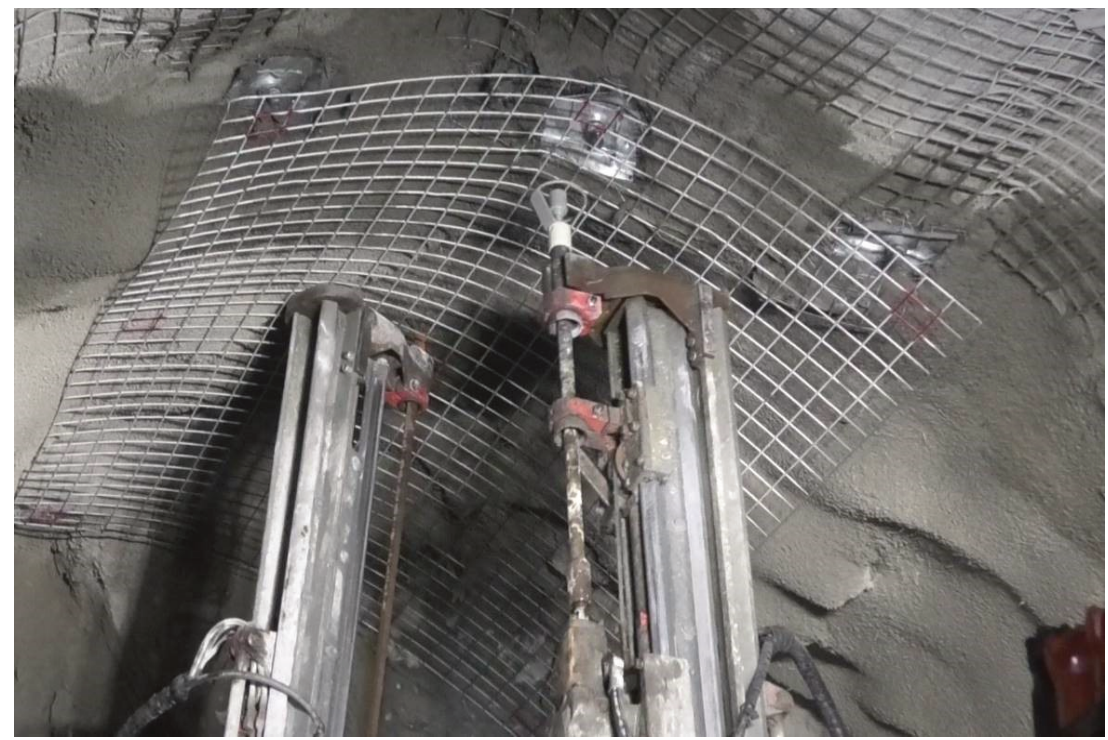

Figure 4 Positioning the mesh clamp onto an existing MD/MDX bolt

Step 4: Rotate the mesh clamp anti-clockwise until the adapter sleeve is tight on the blind nut, continue rotating until the shear pin shears and the cage starts to tighten up to the mesh.

Step 5: The mesh clamp cage can be left loose at this stage to enable the alignment of the sheet of mesh with the adjoining corner MD/MDX bolt, then the next new centre bolt can be installed to secure the sheet of mesh in its correct place.

Step 6: The mesh clamp can then be fully tightened securing the overlapped mesh. 
The next sheet of mesh can then be positioned, and another mesh clamp installed on the existing MD/MDX bolt in the overlapping corner position and so on (Figure 5) until all the new sheets of mesh are installed.

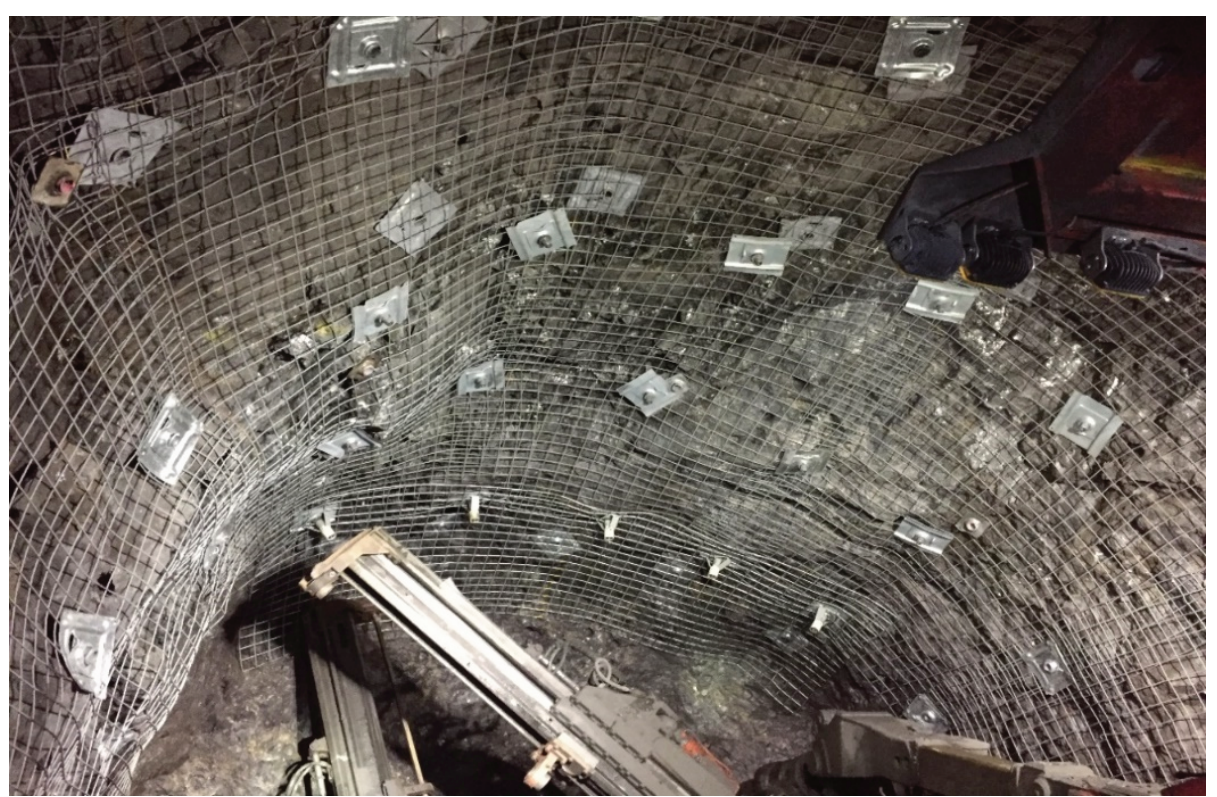

\section{Figure 5 Continuing to install the ring of mesh using the mesh clamp on existing MD/MDX bolts}

The feedback from the operator during the development cycle trial was positive; however, from a development aspect the installed height of the mesh clamp was considered too long. To minimise the installed height to an acceptable level, the ability to pick up a sheet of mesh with the mesh clamp was relinquished. Final prototypes were made, trialled and accepted from a functionality and installed height aspect. Now there was one final item remaining: to evaluate the performance of the system, the sheet of mesh and mesh clamp, under loading conditions. So a load simulation test was required.

\subsection{Evaluation of the system}

Through the development of the mesh clamp, Sandvik identified the need for a device that simulated loading of a sheet of mesh whilst being restrained by various ground support options. To fulfil this need, Sandvik designed and constructed a test rig, which was installed within a hydraulic press to simulate the relevant test environments and severe, steep angled, loading conditions. The test rig (Figure 6) is capable of testing a piece of mesh that is secured to the installation plates.

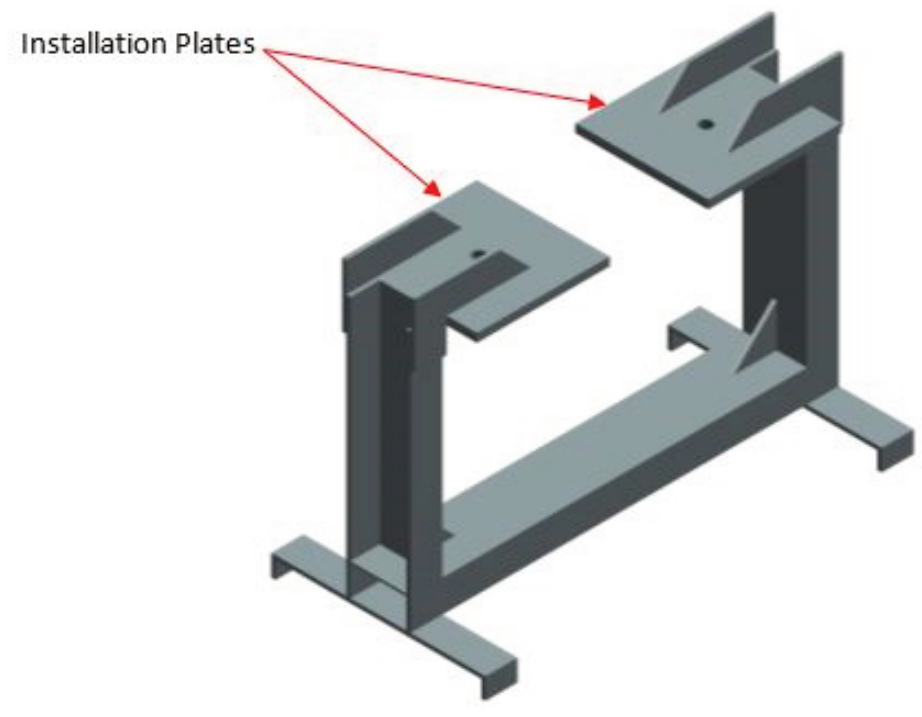

Figure 6 Sandvik mesh system test rig 
The installation plates have holes that are $529 \mathrm{~mm}$ apart and allow the mesh to be secured to them via various methods. A vertical load can be applied to the mesh for a distance of around $270 \mathrm{~mm}$, via a $200 \mathrm{~mm}$ wide by $500 \mathrm{~mm}$ long load plate. This load plate is bolted to the piston rod of the press (Figure 7) which has a maximum stroke of $300 \mathrm{~mm}$.

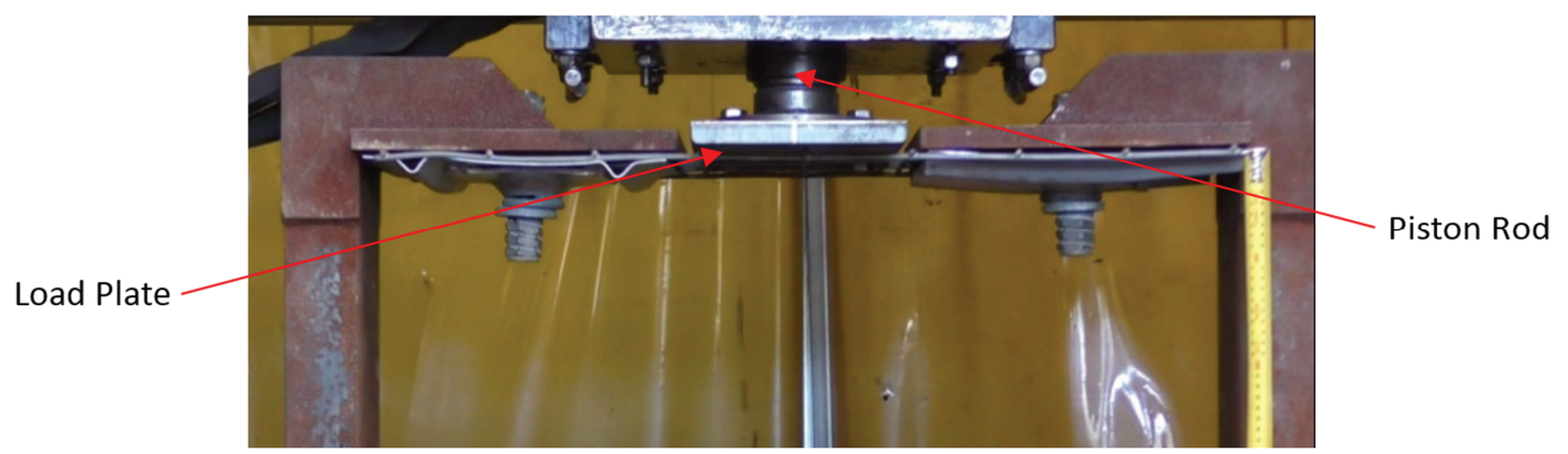

\section{Figure 7 Sandvik mesh system test rig load plate}

In order to verify the performance of the mesh and mesh clamp system, a baseline representing the current meshing practice was required. This was achieved through clamping a piece of mesh to the installation plates using two combination plates with short partial MD bolts tightened to $450 \mathrm{Nm}$. These combination plates are constructed with a $150 \times 150 \times 6 \mathrm{~mm}$ domed rock plate welded to a $2 \mathrm{~mm}$ thick butterfly plate (Figure 8).

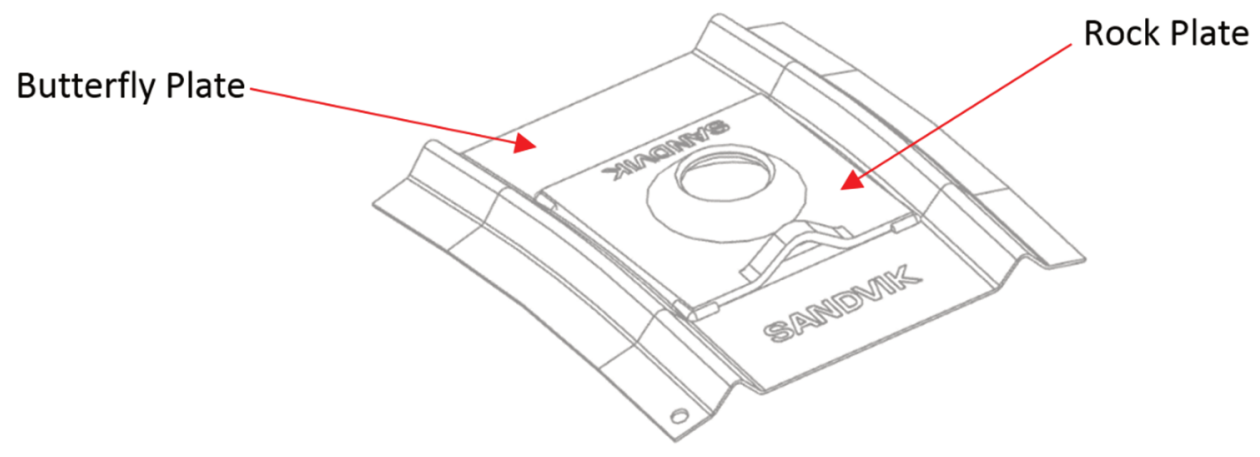

\section{Figure 8 Sandvik combination plate}

The mesh used in the testing was welded mesh with a $100 \times 100 \mathrm{~mm}$ aperture size and $5.6 \mathrm{~mm}$ wire strand diameter, as this is a commonly used mesh in mines. A piece was cut at $800 \times 300 \mathrm{~mm}$ for each test.

The arrangement for the baseline test can be seen in Figure 9. The combination plates were orientated in opposite directions on each MD bolt to simulate different installation arrangements.

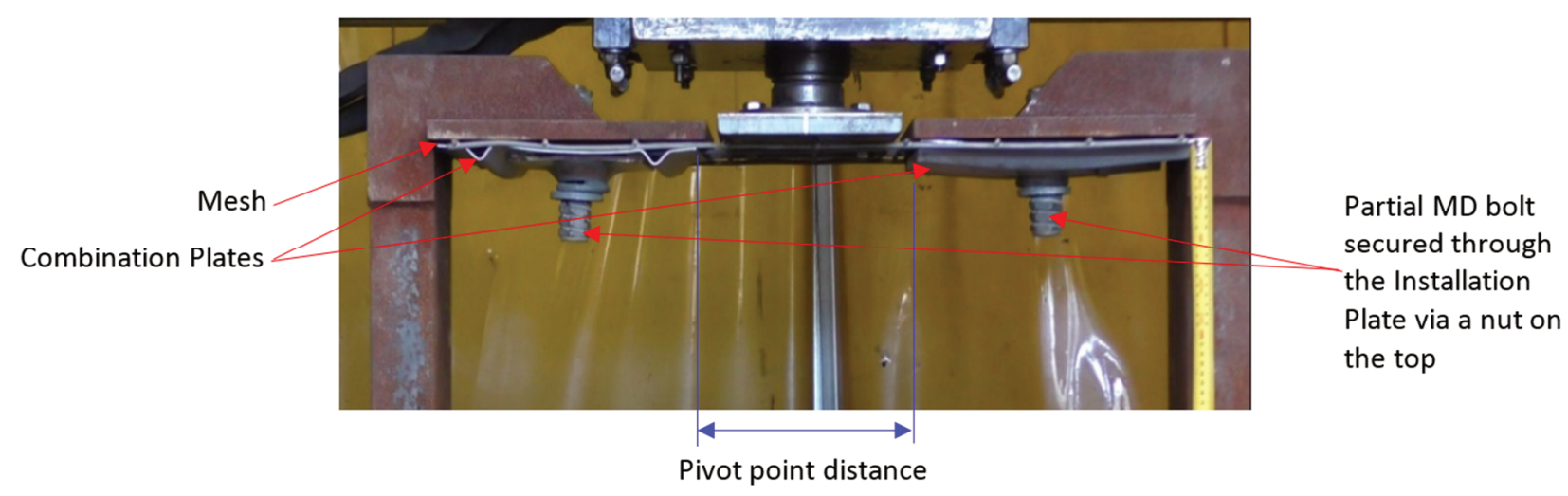

Figure 9 Sandvik mesh system test rig arrangement for baseline test 
The mesh clamp and mesh system were then tested by clamping the piece of mesh with two mesh clamps, tightened to $450 \mathrm{Nm}$, onto two partial MD bolts installed on the test rig (Figure 10). The mesh clamps and combination plates were orientated in opposite directions on each MD bolt to simulate different installation arrangements.

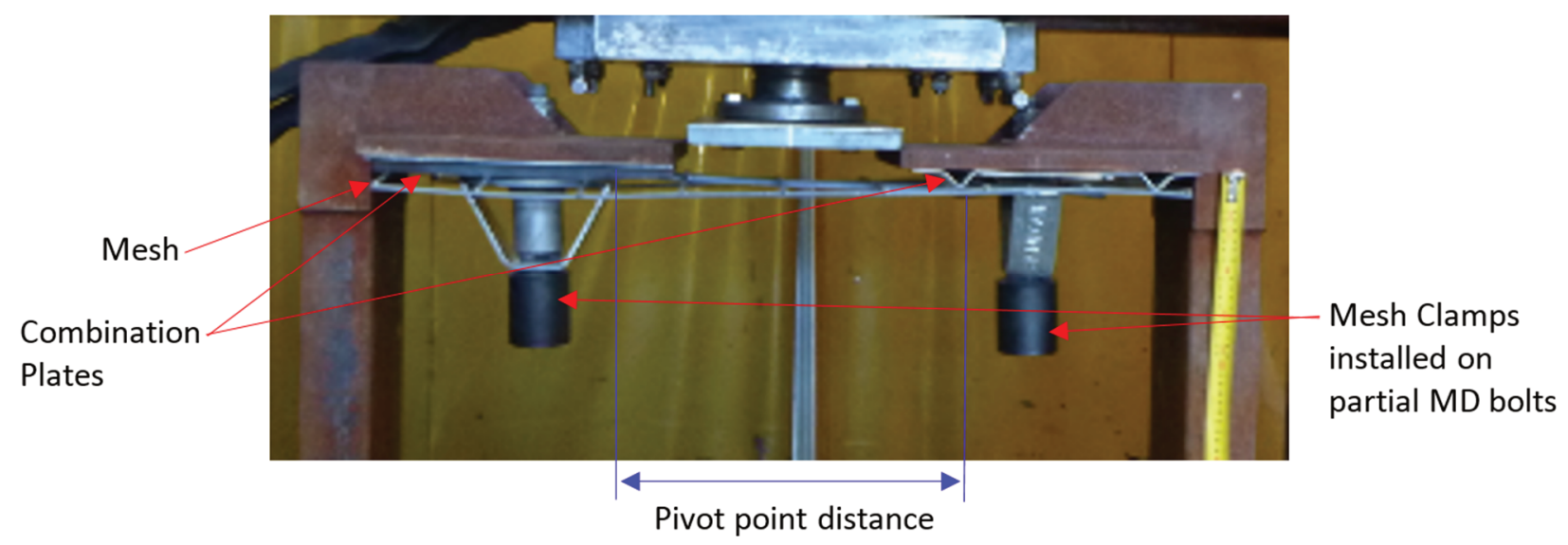

Figure 10 Sandvik mesh system test rig arrangement for mesh clamp and mesh system test

Further tests were conducted on the mesh clamp and mesh system samples to gather more data and then a final test was conducted using production sample mesh clamps.

\section{Testing data}

The load versus displacement data for the baseline test is shown in Table 1.

Table 1 Data from baseline test

\begin{tabular}{llll}
\hline $\begin{array}{l}\text { Item } \\
\text { no. }\end{array}$ & $\begin{array}{l}\text { Load } \\
(\mathbf{k N})\end{array}$ & $\begin{array}{l}\text { Cumulative } \\
\text { displacement }(\mathbf{m m})\end{array}$ & Comments \\
\hline 1 & 0 & 0 & - \\
2 & 9 & 38 & - \\
3 & 15 & 46 & - \\
4 & 17.5 & 49 & - \\
5 & 21 & 56 & - \\
6 & 26 & 60 & - \\
7 & 31 & 65 & - \\
8 & 35 & 72 & - \\
9 & 40 & 77 & - \\
10 & 45 & 85 & - \\
11 & 48 & 90 & First failure; second and third main wires from the front, \\
& & & between fourth and fifth cross wires from the right hand side \\
& & & (RHS) - wires failed. \\
\hline
\end{tabular}


The load versus displacement data for the first mesh clamp and mesh system test is shown in Table 2.

Table 2 Data from the first mesh clamp and mesh system test

\begin{tabular}{|c|c|c|c|}
\hline $\begin{array}{l}\text { Item } \\
\text { no. }\end{array}$ & $\begin{array}{l}\text { Load } \\
\text { (kN) }\end{array}$ & $\begin{array}{l}\text { Cumulative } \\
\text { displacement }(\mathrm{mm})\end{array}$ & Comments \\
\hline 1 & 0 & 0 & - \\
\hline 2 & 10 & 20 & - \\
\hline 3 & 15 & 51 & - \\
\hline 4 & 20 & 88 & Settling on left hand side (LHS) \\
\hline 5 & 25 & 109 & - \\
\hline 6 & 30 & 120 & - \\
\hline 7 & 35 & 131 & - \\
\hline 8 & 40 & 138 & - \\
\hline 9 & 45 & 143 & $\begin{array}{l}\text { First failure; second main wire from the front, between third } \\
\text { and fourth cross wires from the LHS - wire failure }\end{array}$ \\
\hline 10 & 50 & 168 & $\begin{array}{l}\text { Second failure; second main wire from the front and second } \\
\text { cross wire from the LHS - weld failure }\end{array}$ \\
\hline 11 & 50 & 182 & $\begin{array}{l}\text { Third failure; second and third main wire from the front and } \\
\text { second cross wire from the RHS - weld failures }\end{array}$ \\
\hline 12 & 37 & 206 & $\begin{array}{l}\text { Fourth failure; first main wire from the front and second cross } \\
\text { wire from RHS - weld failure }\end{array}$ \\
\hline 13 & 40 & 234 & $\begin{array}{l}\text { Fifth failure; second main wire from the front and third cross } \\
\text { wire LHS - wire at weld failure }\end{array}$ \\
\hline 14 & 40 & 250 & Test stopped; mesh started to slide down on LHS \\
\hline
\end{tabular}


The load versus displacement data for the second mesh clamp and mesh system test is shown in Table 3 .

Table 3 Data from the second mesh clamp and mesh system test

\begin{tabular}{|c|c|c|c|}
\hline $\begin{array}{l}\text { Item } \\
\text { no. }\end{array}$ & $\begin{array}{l}\text { Load } \\
(\mathrm{kN})\end{array}$ & $\begin{array}{l}\text { Cumulative } \\
\text { displacement }(\mathrm{mm})\end{array}$ & Comments \\
\hline 1 & 0 & 0 & - \\
\hline 2 & 5 & 24 & - \\
\hline 3 & 11 & 52 & - \\
\hline 4 & 14 & 71 & $\begin{array}{l}\text { Third cross wire from LHS moved from behind the } \\
\text { combination plate hanger loop }\end{array}$ \\
\hline 5 & 16 & 87 & - \\
\hline 6 & 20 & 109 & - \\
\hline 7 & 25 & 121 & - \\
\hline 8 & 31 & 132 & $\begin{array}{l}\text { First failure; second main wire from the front and second } \\
\text { cross wire from the LHS - weld failures }\end{array}$ \\
\hline 9 & 28 & 149 & $\begin{array}{l}\text { Second failure; second main wire from the front and second } \\
\text { cross wire from the RHS - weld failure }\end{array}$ \\
\hline 10 & 25 & 174 & $\begin{array}{l}\text { Third failure; first main wire from the front and second cross } \\
\text { wire from the RHS - weld failure }\end{array}$ \\
\hline 11 & 18 & 190 & $\begin{array}{l}\text { Fourth failure; second main wire from the front and second } \\
\text { cross wire from RHS - second cross wire failed through weld }\end{array}$ \\
\hline 12 & 20 & 205 & - \\
\hline 13 & 25 & 224 & - \\
\hline 14 & 31 & 232 & - \\
\hline \multirow[t]{2}{*}{15} & 35 & 243 & $\begin{array}{l}\text { Fifth failure; second main wire from the front and second } \\
\text { cross wire from LHS - second cross wire failed through weld }\end{array}$ \\
\hline & & & $\begin{array}{l}\text { Sixth failure; second main wire from the front and first cross } \\
\text { wire RHS - weld failure }\end{array}$ \\
\hline 16 & 31 & 257 & Test stopped; end of press cylinder stroke \\
\hline
\end{tabular}


The load versus displacement data for the third, production sample, mesh clamp and mesh system test is shown in Table 4.

Table 4 Data from the third, production sample, mesh clamp and mesh system test

\begin{tabular}{|c|c|c|c|}
\hline $\begin{array}{l}\text { Item } \\
\text { no. }\end{array}$ & $\begin{array}{l}\text { Load } \\
\text { (kN) }\end{array}$ & $\begin{array}{l}\text { Cumulative } \\
\text { displacement }(\mathrm{mm})\end{array}$ & Comments \\
\hline 1 & 0 & 0 & - \\
\hline 2 & 9 & 21 & - \\
\hline 3 & 13 & 56 & - \\
\hline 4 & 17.5 & 92 & $\begin{array}{l}\text { Third cross wire from LHS moved from behind the } \\
\text { combination plate hanger loop }\end{array}$ \\
\hline 5 & 21 & 114 & - \\
\hline 6 & 26 & 126 & - \\
\hline 7 & 31 & 140 & $\begin{array}{l}\text { First failure; second main wire from the front and second } \\
\text { cross wire from the RHS - second cross wire failed through } \\
\text { weld }\end{array}$ \\
\hline 8 & 21 & 182 & - \\
\hline 9 & 31 & 203 & $\begin{array}{l}\text { Second failure; third main wire from the front and second } \\
\text { cross wire from the LHS - weld failure }\end{array}$ \\
\hline 10 & 30 & 215 & $\begin{array}{l}\text { Third failure; third main wire from the front and third cross } \\
\text { wire from the LHS - weld failure }\end{array}$ \\
\hline 11 & 26 & 236 & $\begin{array}{l}\text { Fourth failure; second main wire from the front and third } \\
\text { cross wire from LHS - third cross wire failed through weld }\end{array}$ \\
\hline 12 & 31 & 254 & $\begin{array}{l}\text { Fifth failure; second main wire from the front and second } \\
\text { cross wire from LHS - weld failure }\end{array}$ \\
\hline 13 & 26 & 272 & Test stopped; end of press cylinder stroke \\
\hline
\end{tabular}

\section{$4 \quad$ Discussion of results}

The baseline test results showed little to no slippage of the mesh between the combination plate and the installation plates of the test rig. This led to the failure of the two centre longitudinal wires (Figures 11 and 12) at a load of $48 \mathrm{kN}$ and a displacement of $90 \mathrm{~mm}$.

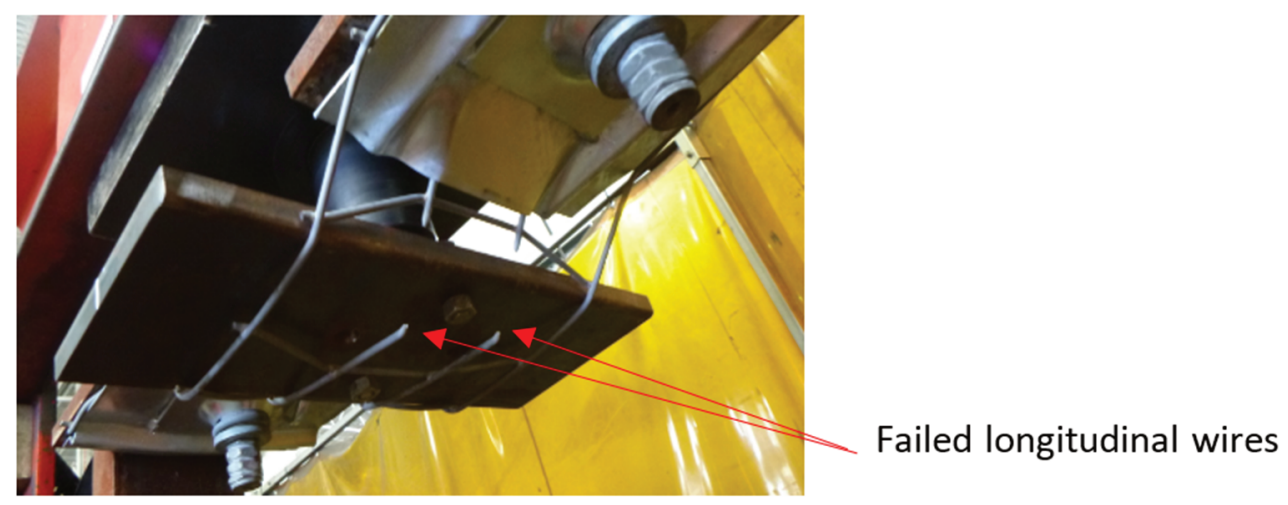

Figure 11 Baseline test - failure of longitudinal wires 


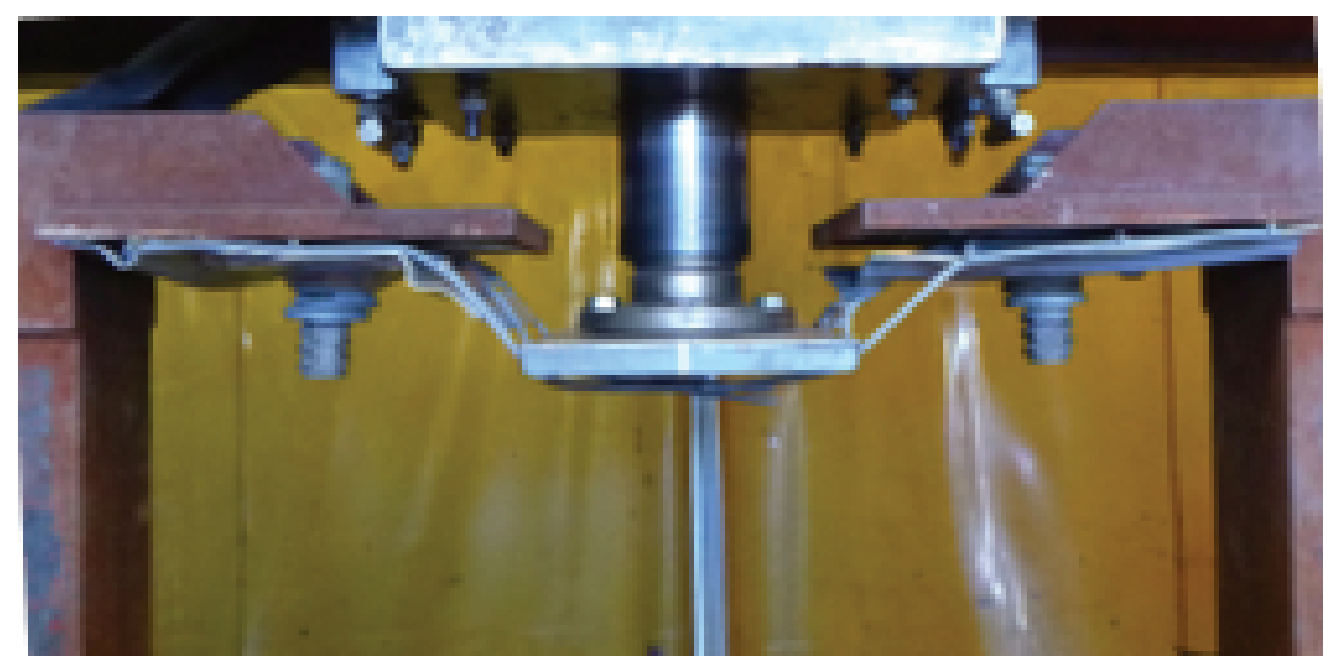

Figure 12 Baseline test - mesh at longitudinal wire failures

Figure 13 shows the load versus displacement characteristics for the baseline test.

Load versus displacement

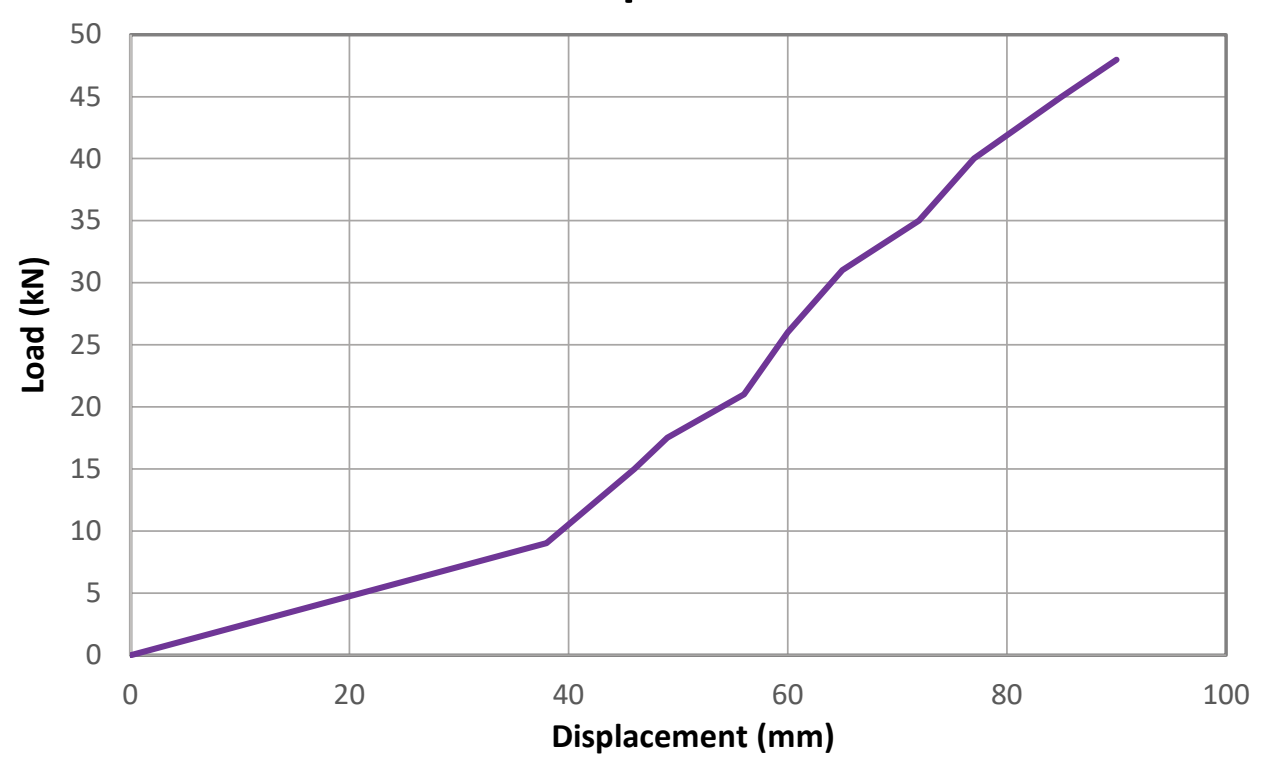

Figure 13 Displacement response to loading for the baseline test

The first mesh clamp and mesh system tested met the design criteria. That is the mesh was the point of failure rather than the mesh clamp, and the mesh clamp did not compromise the strength of the mesh, as there are no sharp edges to create notches in the wires.

The first point of failure was the breakage of the second main mesh wire from the front on the LHS of the test rig. The displacement of the load plate at this point was $143 \mathrm{~mm}$ with an applied load of $45 \mathrm{kN}$. The mesh clamp and mesh system continue to take load and deform until $250 \mathrm{~mm}$ when the test was stopped due to the mesh starting to slide down on the LHS. The mesh failed at a maximum load of $50 \mathrm{kN}$.

Figure 14 shows the load versus displacement characteristics for the first mesh clamp and mesh system test. 


\section{Load versus displacement}

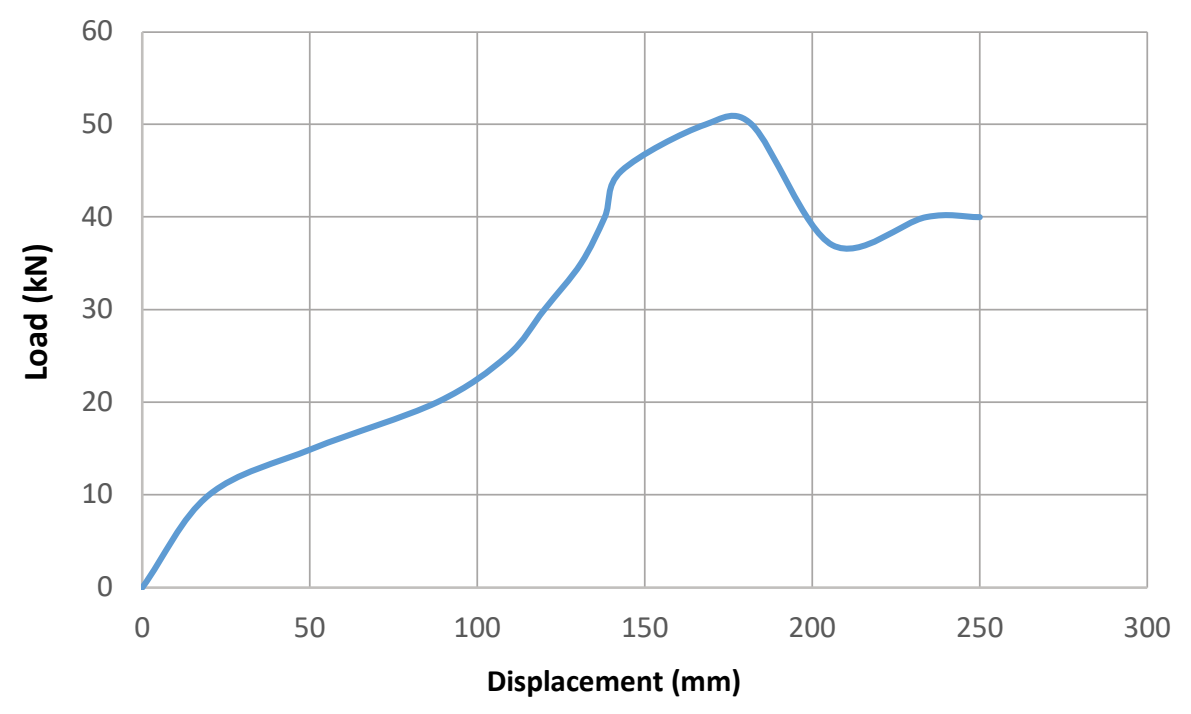

Figure 14 Displacement response to loading for the first mesh clamp and mesh system test

The required design criteria were also met on the second test of the mesh clamp and mesh system. The first point of failure was the breakage of the weld between the second main mesh wire from the front and the second cross wire from the LHS of the test rig. The displacement of the load plate at this point was $132 \mathrm{~mm}$ with a $31 \mathrm{kN}$ applied load. The mesh clamp and mesh system continued to take load and deform until $257 \mathrm{~mm}$ where the test was stopped due to maximum press cylinder stroke. The mesh failed at a maximum load of $35 \mathrm{kN}$.

Figure 15 shows the load versus displacement characteristics for the second mesh clamp and mesh system test.

\section{Load versus displacement}

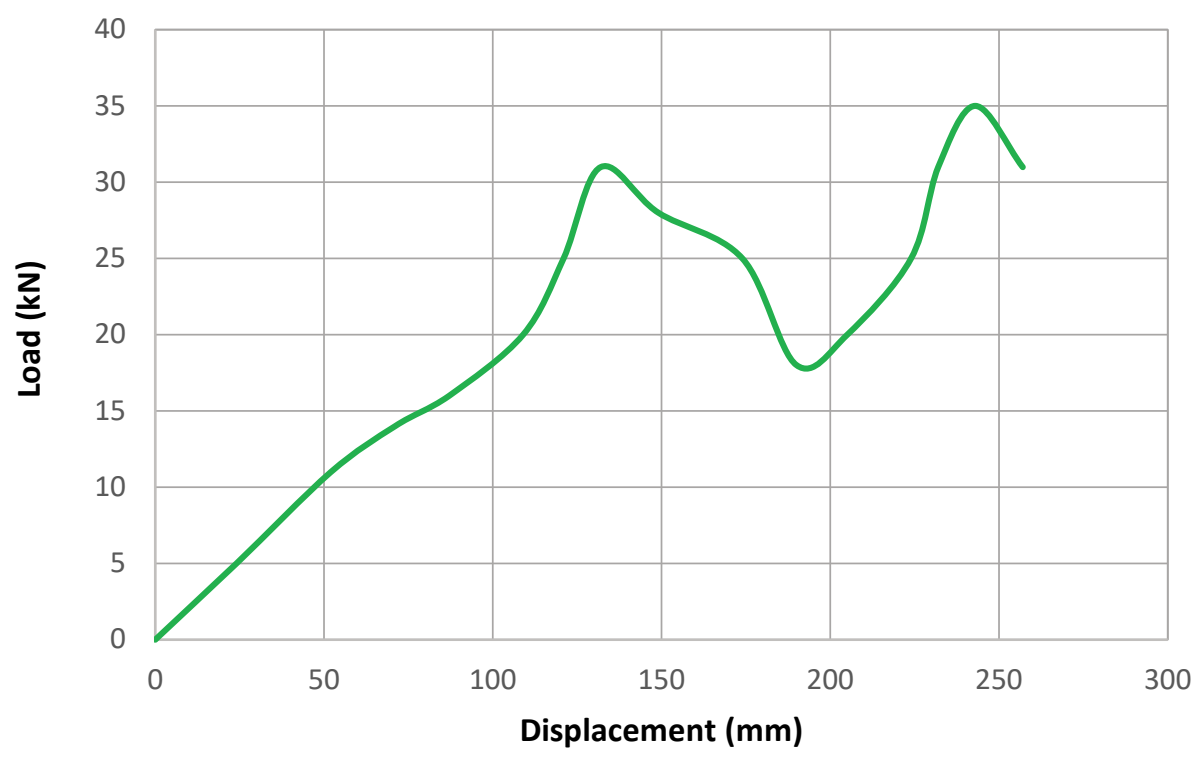

Figure 15 Displacement response to loading for the second mesh clamp and mesh system test

The required design criteria were met again on the third test, which was of the production mesh clamp samples and the mesh. The first point of failure was the breakage of the second cross wire from the RHS of 
the test rig, through the weld between itself and the second main mesh wire from the front. The displacement of the load plate at this point was $140 \mathrm{~mm}$ with a $31 \mathrm{kN}$ applied load. The mesh clamp and mesh system continue to take load and deform until $272 \mathrm{~mm}$ where the test was stopped due to maximum press cylinder stroke. The mesh failed at a maximum load of $31 \mathrm{kN}$.

Figure 16 shows the load versus displacement characteristics for the production sample mesh clamp and mesh system test.

\section{Load versus displacement}

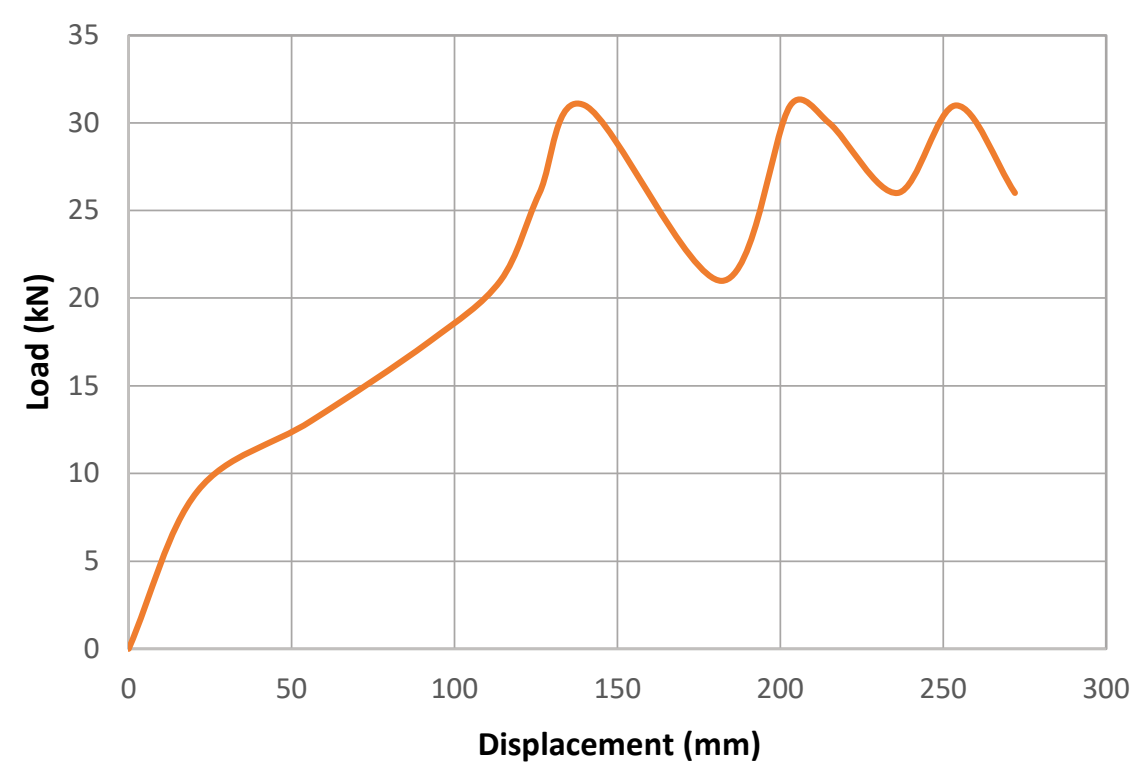

Figure 16 Displacement response to loading for the production sample mesh clamp and mesh system test

Figure 17 shows the deformation of the mesh at the end of the production sample mesh clamp and mesh system test, after $272 \mathrm{~mm}$ displacement.

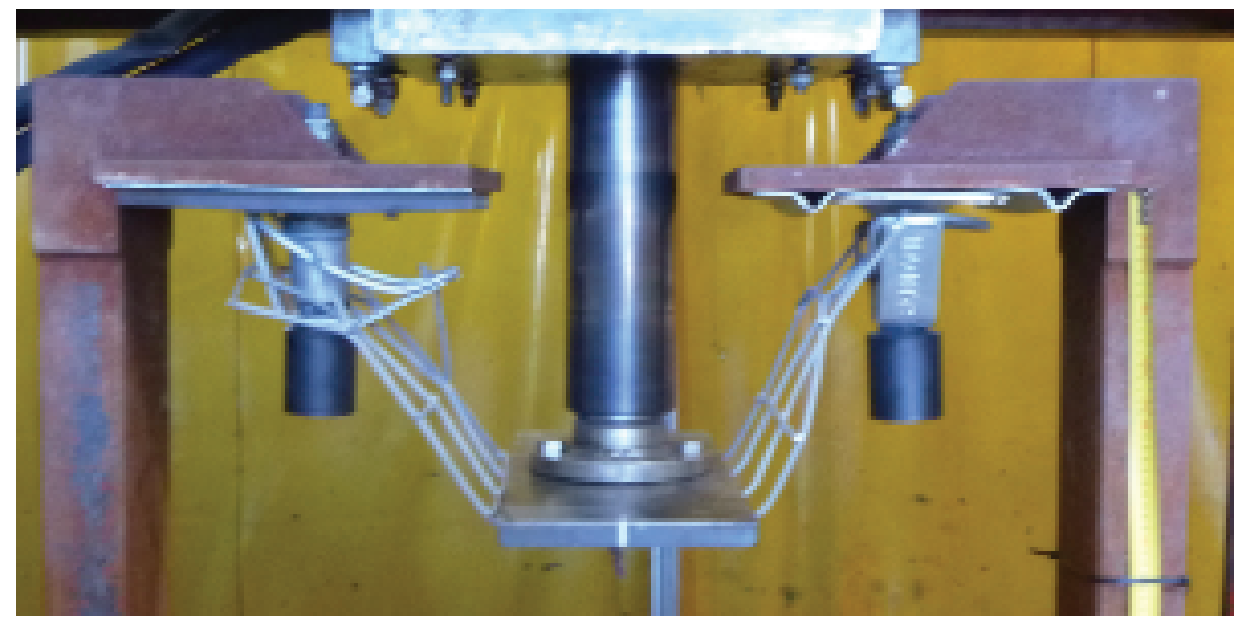

Figure 17 Production sample mesh clamp and mesh system test - after $272 \mathrm{~mm}$ displacement

Comparing the three mesh clamp and mesh system tests with the baseline test (Figure 18), the combination plate allowed the mesh to show a stiffer response to the load. This could be contributed to the large flat clamping area between the installation plates and the combination plate. Additionally, a comparison of the pivot point distances between the baseline and mesh clamps test showed a narrower pivot point distance for the baseline test. 


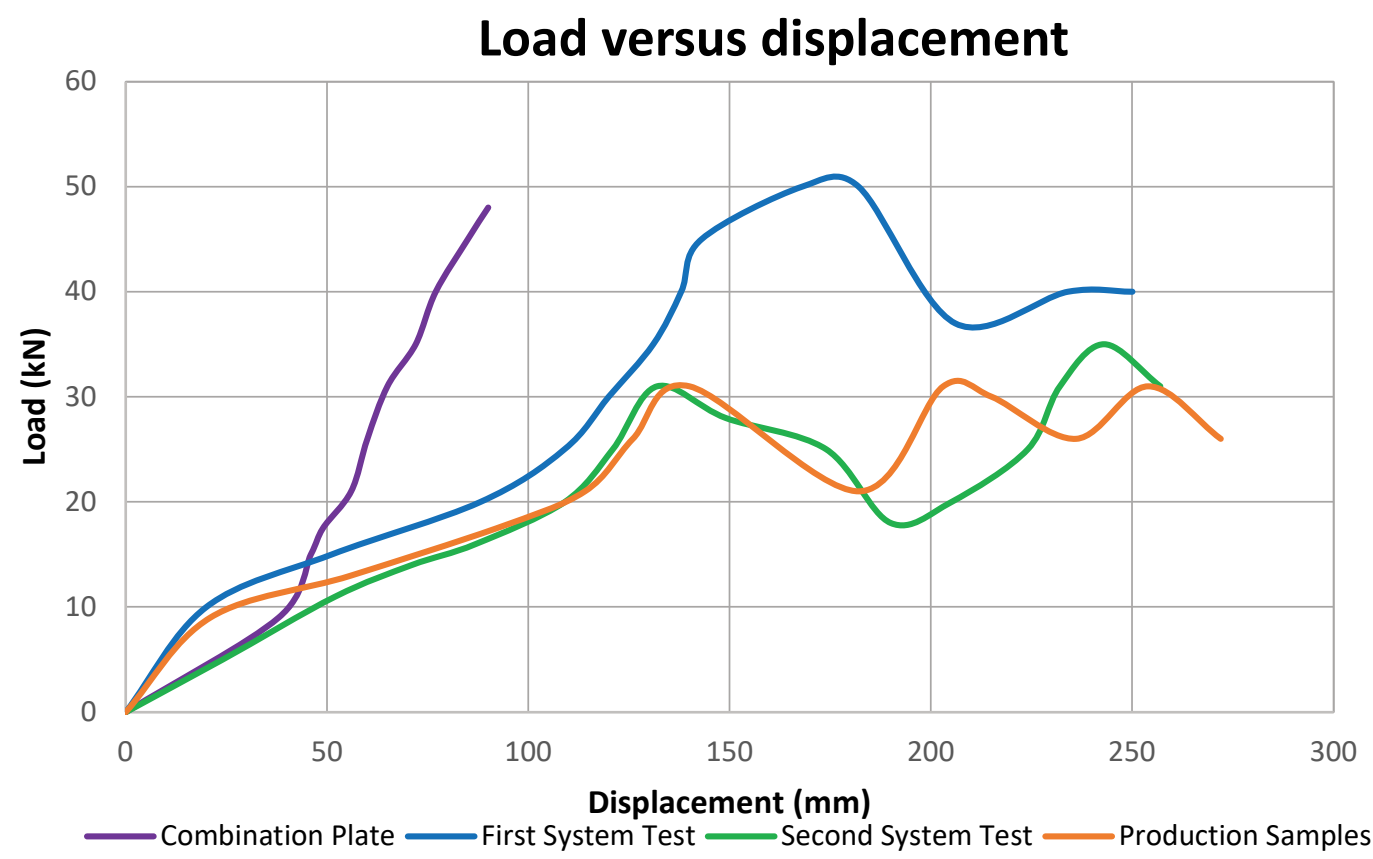

Figure 18 Summary of displacement response to loading for all tests

The three mesh clamp and mesh tests overall performed similarly, where the difference between the maximum loads are attributed to the difference in strength of the failure points, i.e. the wire strength is approximately $50 \mathrm{kN}$, versus the weld strength of approximately $30 \mathrm{kN}$.

\section{Conclusion}

The test rig was successfully used to simulate severe loading of mesh through the steep mesh deformation angle. The combination plate and mesh test provided a baseline of the current meshing practice as well as confirming the typical mesh wire strength.

The combination plate test simulated a better case scenario due to the flat clamping area/surface described in this paper, where the mesh clamp simulated an extreme scenario where only one layer of mesh was clamped. Typically, in the underground environment, there would be overlapping mesh.

The required design criteria were met from the outcomes of the mesh clamp and mesh system tests:

- The mesh was the point of failure rather than the mesh clamp.

- The mesh clamp did not compromise the strength of the mesh as there are no sharp edges to create notches in the wires.

The mesh clamp deformed, in conjunction with the mesh as it was loaded, allowing it to continue to provide support to the mesh.

\section{Acknowledgement}

During the process of the design and testing of the mesh clamp, the work was the joint effort of the authors along with Peter Young; Sandvik's Global Product Line Manager - Bolting Products, and the employees of Barminco and MMG at Dugald River Mine.

\section{References}

Whiting, RK 2017, 'In situ static performance assessment of mine mesh', in J Wesseloo (ed.), Proceedings of the Eighth International Conference on Deep and High Stress Mining, Australian Centre for Geomechanics, Perth, pp. 747-762, https://doi.org/10.36487/ACG_rep/1704_51_Whiting 
